\title{
Lower Limb Muscles Activity and Inclined Squat Position in Normal Children (Cross Sectional Study)
}

\author{
Ahmed A. Allam*1, Emam H. Elnegmy², Mahmoud S. El Fakharany ${ }^{2}$ \\ ${ }^{1}$ Captain Physiotherapist at Al Agouza Police Hospital. \\ ${ }^{2}$ Department of Physical Therapy for Pediatrics, Faculty of Physical Therapy, Cairo University \\ *Corresponding author: Ahmed A. Allam, Mobile: (+20) 01094660443, E-Mail: Ahmadallam92@gmail.com
}

\begin{abstract}
Background: Benefits associated with squat performance are not limited to the athletic population. Given that most activities of daily living necessitate the simultaneous coordinated interaction of numerous muscle groups, the squat is considered one of the best exercises for improving quality of life because of its ability to recruit multiple muscle groups in a single maneuver.
\end{abstract}

Objective: To determine the effect of inclined squat position on the vastus medialis oblique (VMO) and gluteus maximus $(\mathrm{GM})$ at the different ankle angles $5^{\circ}-10^{\circ}$ degrees of inclination in normal children.

Subjects and methods: thirty non-athletic children of both genders, age ranged from 14 to 18 years, were selected from the Egyptian governmental schools at Sixth of October City and Sixth of October Sporting Club. The maximum voluntary isometric contraction (MVIC) was measured after the electrodes were attached to the GM and the VMO of the subject during squat postures which applied on two inclined borders 5 and 10 degree of inclination; the feet are spread out shoulder width, hip $70^{\circ}$ flexion, knee $75^{\circ}$ flexion and in the erect posture.

Results: There was a significant increase in the VMO activity in $5^{\circ}$ ankle angle compared with that of $10^{\circ}$ ankle angle $(\mathrm{p}=0.0001)$. There was a significant decrease in the GM activity in $5^{\circ}$ ankle angle compared with that of $10^{\circ}$ ankle angle $(\mathrm{p}=0.0001)$.

Conclusion: modification of ankle dorsiflexion during squat position should be integrated in the rehabilitation programs of the different injuries.

Keywords: Squat Position, Muscles Activity, Isometric contraction, Electromyography.

\section{INTRODUCTION}

Squat exercise is the most commonly used exercise among various weight training methods because it is easily accessible without using tools ${ }^{(\mathbf{1})}$. Squat exercises strengthen the gluteal, quadriceps, and trunk muscles that are important for running, jumping, and lifting (2).

Squat movements are more advantageous than non-weight bearing exercises by moving many joints, mobilizing more muscles, and stimulating proprioceptive more strongly ${ }^{(3)}$.

The squat is a well-known exercise for the knee and hip muscles and is commonly used in rehab programs. Biomechanically, the squat is a close-chain movement, requiring simultaneous extension patterns of the ankle, knee and hip joints. The squat can be performed in many different ways, including variations in foot width (sumo squats), foot position (single leg squats, Bulgarian squats), load position (front squats, sissy squats) and depth (full range squats, shallow squats). However, it is important to keep in mind that each one of these variations will influence knee joint forces and muscle recruitment patterns.

For example, there was much debate about the safety of deep (full range) squats. Coaches often define a full range squat by amount knee range of motion (120140 degrees), or by observation of the thigh angle (below parallel to the floor) ${ }^{(4)}$.
Isometrically, the lower back, the upper back, the abdominals, the trunk muscles, the costal muscles, and the shoulders and arms are all essential to the exercise and thus are trained when squatting with the proper form ${ }^{(5)}$.

The electromyography (EMG) signal is electrical indication of the neuromuscular actuation connected with a contracting muscle. It is an exceedingly complicated sign which is influenced by the anatomical and physiological properties of muscles, the control plan of the fringe sensory system, and also the attributes of the instrumentation that is utilized to identify and watch it ${ }^{\left({ }^{(}\right)}$.

EMG is measuring the electrical sign connected with the enactment of the muscle. This may be willful or automatic muscle compression. The EMG action of willful muscle withdrawals is identified with pressure (7). This study aimed to determine the effect of inclined squat position on the vastus medialis oblique (VMO) and gluteus maximus (GM) at the different ankle angles $5^{\circ}-10^{\circ}$ degrees of inclination in normal children.

\section{SUBJECTS AND METHODS}

The subjects included 30 non-athletic children of both genders, age ranged from 14 to 18 years, were selected from the Egyptian governmental schools at Sixth of October City and Sixth of October Sporting Club, the subjects were selected with inclusion criteria

This article is an open access article distributed under the terms and conditions of the Creative Commons Attribution (CC BY-SA) license (http://creativecommons.org/licenses/by/4.0/) 
including, the ability to maintain proper position of both legs and feet during examination, able to follow instructions and understand commands given to them and had normal body physical function. The subjects who had one or more of the following criteria were excluded from the study; bone and joint diseases, lower limb surgery, leg length discrepancy, poor balance, abnormal gait pattern or foot or lower limb deformity.

\section{Ethical consideration:}

Written informed consent was obtained from each child to be participated in this study.

An approval of the study was obtained from Cairo University academic and ethical committee.

\section{1- Electromyography (EMG) :}

Electromyography (EMG) is diagnostic electrical equipment that evaluates the excitable tissue (the nerves and muscles). The nerve cells are the motor neurons which transmit electrical signals that cause muscles to contract. An EMG represents the most diagnostic method of neuro-muscular system evaluation, able to detect nerve and muscle performance as well as synaptic connection between them ${ }^{(8)}$.

A number of variables are considered in weightlifting and squat-specific studies. Muscle activation during these exercises is one component pertinent to the current study. Muscle activity was examined a number of times in conjunction with the squat exercise and has been subjected to a variety of protocols and analyses. BioTrace+ software for NeXus10 biofeedback system (Mind Media, UK) at a sampling frequency of $2048 \mathrm{~Hz}$ has been heavily used to collect data in such studies as it acquire high quality bioelectrical and other physiological signals and transfer these signals to a computer for processing and analysis as shown in figure (1)

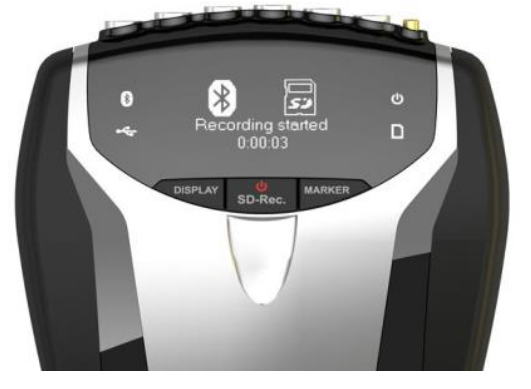

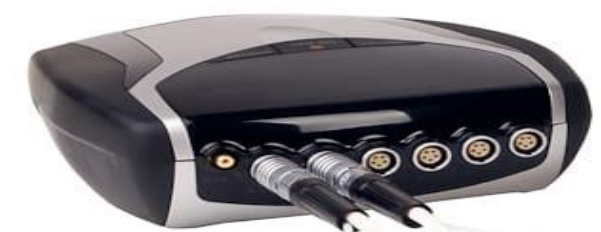

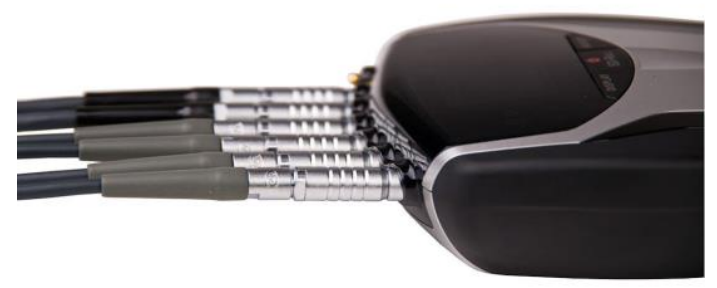

Fig. (1): NeXus-10 biofeedback system.

\section{2- Two inclined boards (5 and 10 degrees):}

The incline board is a flat board that is usually made of a strong wood like birch wood. As the name suggests the peculiarity of this board is that this board is used when it is in a slanting position. The incline that the board can be set up at can be adjusted as per your requirements and the requirements of the exercise, as squat exercise is shown in figure (2).

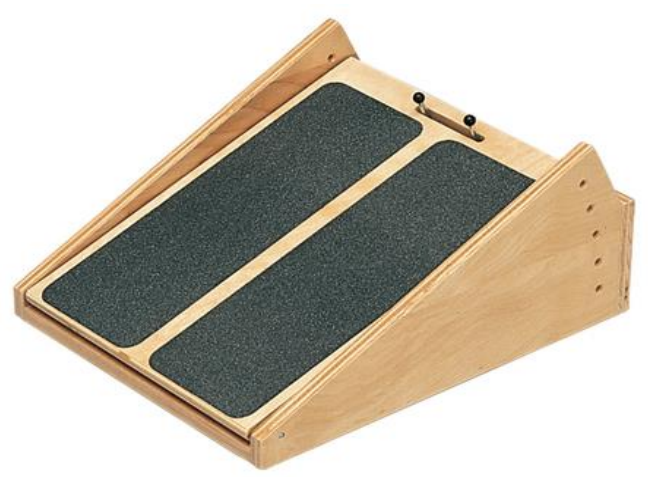

Fig. (2): Inclined board. 


\section{Procedures:}

The maximum voluntary isometric contraction (MVIC) was measured after the electrodes were attached to the GM and the VMO of the subject. Before the experiment, the researchers gave sufficient explanation about the squat position to the subjects and the subjects were able to understand the experimental method by prepracticing each posture at least 2 times. The squat postures were as follows, repeated two times each in a random order:-
Incline $5^{\circ}$ ankle angle while standing on an incline wedge of $5^{\circ}$, the feet were spread out shoulder width, hip $70^{\circ}$ flexion, knee $75^{\circ}$ flexion and in the erect posture, the arm was extended to the height of the shoulder and held at shoulder width. The arms were stretched forward in movement parallel with the floor, and the waist and knee were bent so that the head and knee did not cross the toes while bending the knees up to $95^{\circ}$ in flexion (Figure 3).

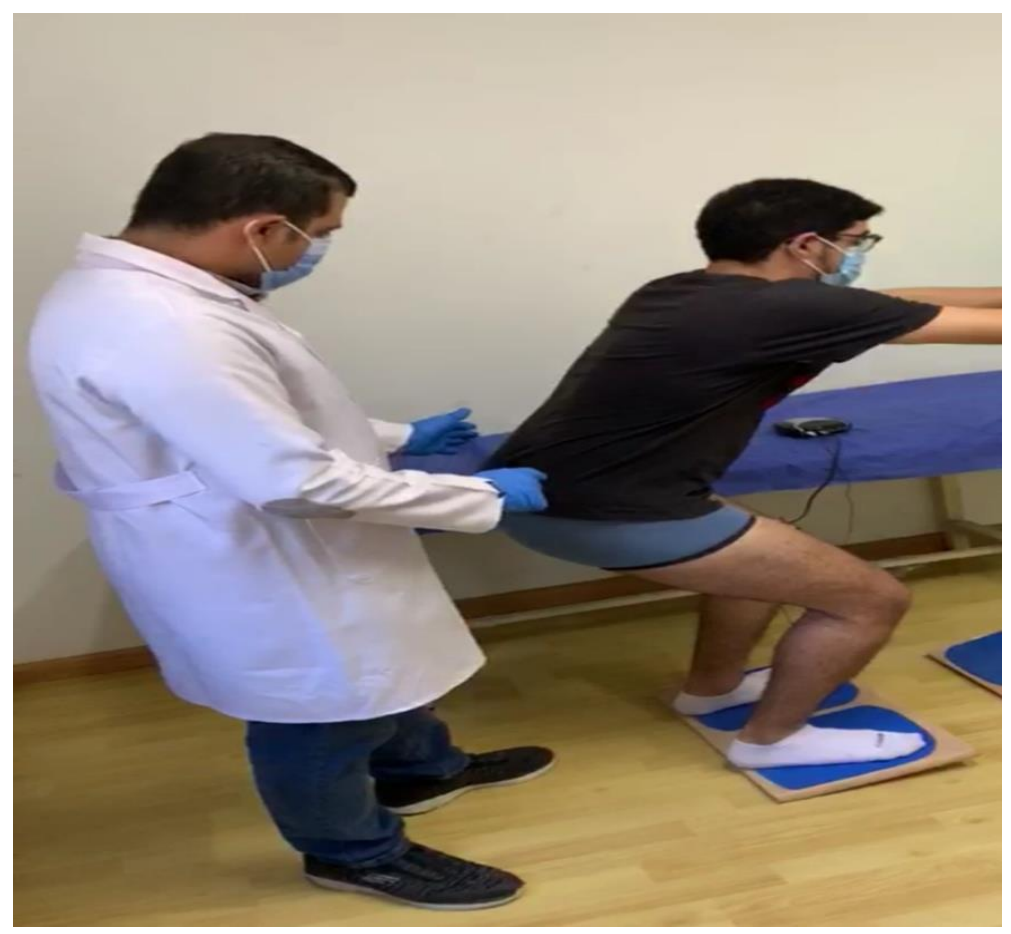

Fig. (3): $5^{\circ}$ incline board squat.

Incline $10^{\circ}$ ankle angle while standing on an incline wedge of $10^{\circ}$, the feet were spread out shoulder width, hip $70^{\circ}$ flexion, knee $75^{\circ}$ flexion and in the erect posture, the arm was extended to the height of the shoulder and held at shoulder width. The arms were stretched forward in movement parallel with the floor, and the waist and knee were bent so that the head and knee did not cross the toes while bending the knees up to $95^{\circ}$ in flexion (Figure 4).

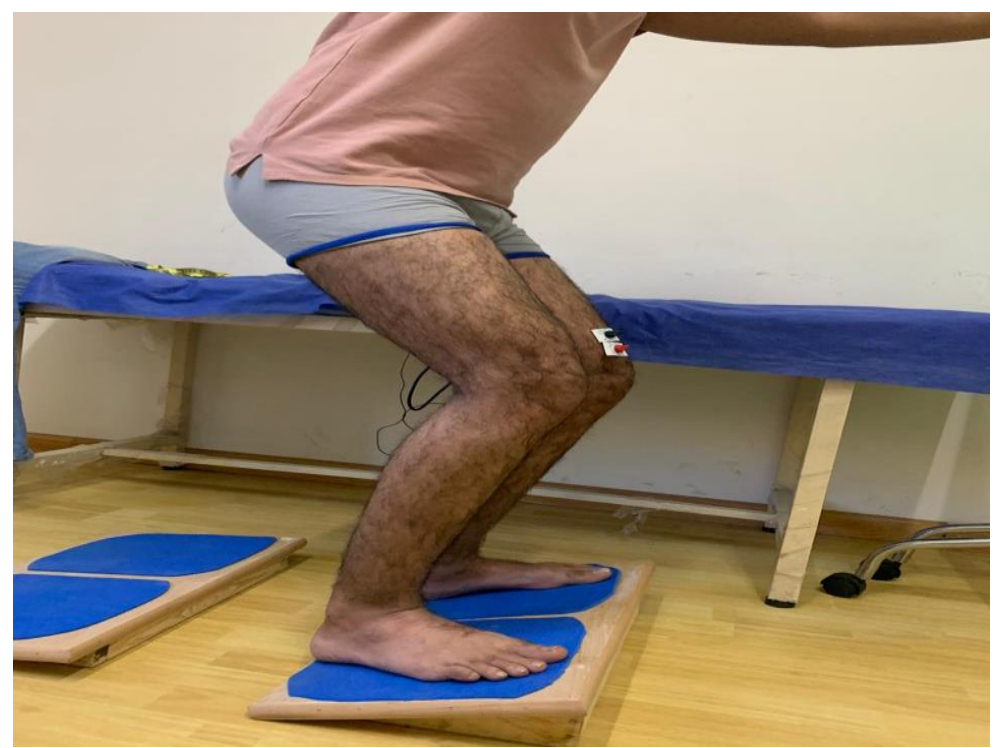

Fig. (4): $10^{\circ}$ incline board squat.

EMG signals were recorded using BioTrace+ software for NeXus-10 biofeedback system at a sampling frequency of 2048Hz. SENIAM recommendations were followed for the skin preparation and sensor locations as shown in figure (5). 


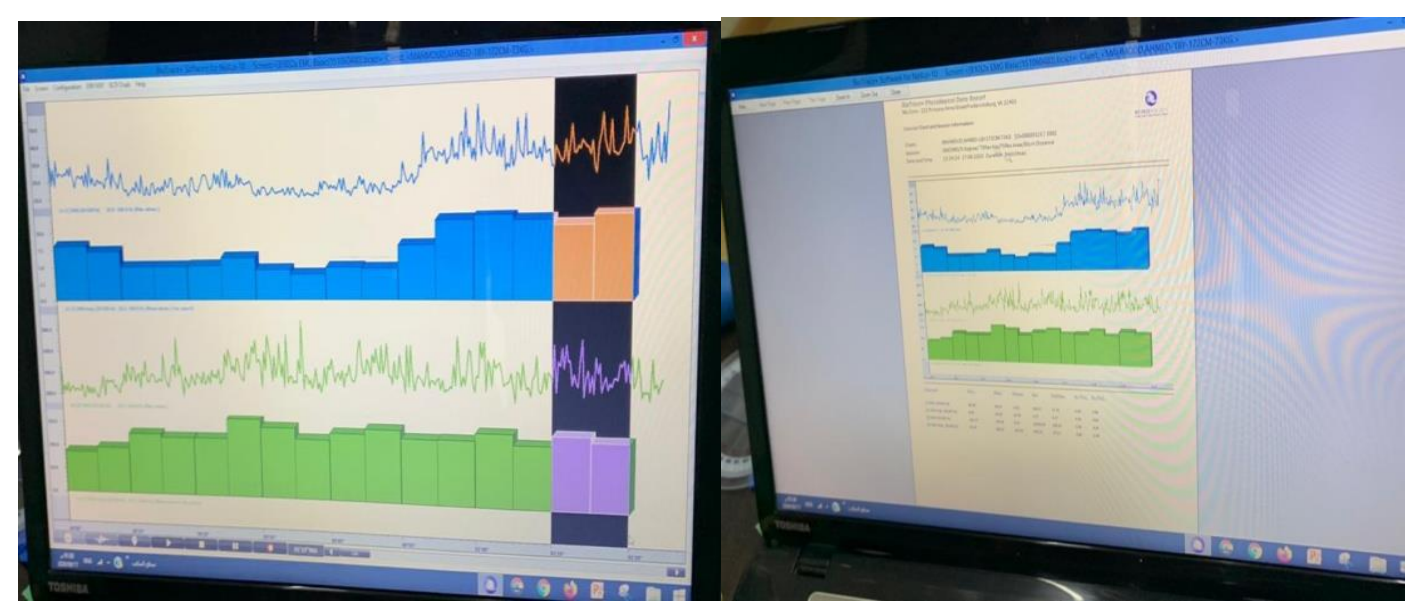

Fig. (5): BioTrace+ software for NeXus-10 biofeedback system.

Electrode sites were shaved and then rubbed with an alcohol-soaked cotton swab to reduce skin impedance. Surface electrodes were positioned at an inter electrode distance of $2 \mathrm{~cm}$. The EMG data were collected for the VMO and GM muscles. The VMO electrode was approximately three-fourths of the thigh length from the anterior inferior iliac spine on the medial side of the thigh. The GM muscle electrode was placed $50 \%$ on the line between the sacral vertebrae and the greater trochanter. This position corresponds with the greatest prominence of the middle of the buttocks well above the visible bulge of the greater trochanter.

A band pass filter was used between 20 and 450 $\mathrm{Hz}$. The raw data were converted into root mean square values measured in a window of $50 \mathrm{~ms}$. Normalization was necessary to minimize variables or differences between different recoding sites and individuals.

\section{Statistical analysis}

Descriptive statistics were conducted for expression of the subject characteristics and measured variables of the study group. They were presented as means, standard deviation (SD), minimum and maximum. The normality of data was checked using Shapiro-Wilk test. Paired t test was performed to compare normalized EMG of VMO and GM between ankle angles $5^{\circ}-10^{\circ}$ degrees. The level of significance for statistical tests was set at $p<0.05$. All statistical analysis was conducted through the statistical package for the social sciences (SPSS) version 22 for windows (IBM SPSS, Chicago, IL, USA).

\section{RESULTS \\ Subject characteristics:}

Thirty children, $21(70 \%)$ males and $9(30 \%)$ females, participated in this study. $27(90 \%)$ of children had the right leg dominant and $3(10 \%)$ had the left side dominant. Subjects' characteristics are present in table 1.

Table 1. Subject characteristics of the study group:

$\mathrm{SD}$, Standard deviation

\begin{tabular}{|l|c|c|c|c|}
\hline & Mean \pm SD & Minimum & Maximum & Range \\
\hline Age (years) & $15.6 \pm 1.24$ & 14 & 18 & 4 \\
\hline Weight $(\mathbf{k g})$ & $61.13 \pm 7.93$ & 47 & 75 & 28 \\
\hline Height $(\mathbf{c m})$ & $164.96 \pm 4.61$ & 154 & 177 & 23 \\
\hline BMI $\left(\mathbf{k g} / \mathbf{m}^{2}\right)$ & $22.44 \pm 2.57$ & 17.47 & 25.95 & 8.48 \\
\hline
\end{tabular}

\section{Effect of ankle angle in normalized EMG of VMO and GM}

There was a significant increase in the VMO activity in $5^{\circ}$ ankle angle compared with that of $10^{\circ}$ ankle angle $(\mathrm{p}<0.001)$.There was a significant decrease in the GM activity in $5^{\circ}$ ankle angle compared with that of $10^{\circ}$ ankle angle $(\mathrm{p}<0.001)$. (Table 2 and figure 6$)$.

Table 2. Mean normalized EMG of VMO GM at ankle angles $5^{\circ}-10^{\circ}$ degrees:

\begin{tabular}{|c|c|c|c|c|c|c|}
\hline & & $\begin{array}{c}5^{\circ} \text { ankle } \\
\text { angle }\end{array}$ & $\begin{array}{c}10^{\circ} \text { ankle } \\
\text { angle }\end{array}$ & & & \\
\hline & & Mean \pm SD & Mean \pm SD & MD $(95 \%$ CI $)$ & t- value & p value \\
\hline \multirow[t]{2}{*}{$\%$ MVIC } & VMO & $83.5 \pm 18.62$ & $74.91 \pm 17.97$ & $8.6(13.6: 16.64)$ & 6.8 & 0.001 \\
\hline & GM & $12.03 \pm 4.3$ & $14.67 \pm 5.15$ & $-2.64(6.63: 9.94)$ & -8.25 & 0.001 \\
\hline
\end{tabular}

$\mathrm{SD}$, Standard deviation; MD, Mean difference; CI, Confidence interval; $\mathrm{p}$-value, Level of significance 


\section{DISCUSSION}

There was a significant increase in the VMO activity in $5^{\circ}$ ankle angle compared with that of $10^{\circ}$ ankle angle. There was a significant decrease in the GM activity in $5^{\circ}$ ankle angle compared with that of $10^{\circ}$ ankle angle.

The movement of the squat was reported to cause simultaneous movement of the ankle joint, knee, and hip joint ${ }^{\left({ }^{9}\right)}$. Donatelli ${ }^{(\mathbf{1 0})}$ found that different muscle activity depends on the angle of flexion of the knee joint. In addition, the body angle increases with increasing instability ${ }^{(11)}$.

The squat movement on the unstable support surface improves the balance of core muscles and enhances the function of the joints and increases the muscle activity of the lower extremity muscles ${ }^{(\mathbf{1 2})}$.

In the present study, it was found that a squat at $10^{\circ}$ of incline angle at the ankle joint increased the muscle activity of the GM more than that of the squat performed at neutral or the squat performed at $5^{\circ}$ of incline angle at the ankle joint. The VMO muscle activity increased, significant difference was found. This is due to the instability due to the movement and reduction of the base of support during the squat movement as the angle of the base plane increases, and the muscle activity of the VMO muscle is increased to overcome this ${ }^{(13)}$.

In addition, increasing the ankle angle causes cocontraction of the muscles to maintain balance due to the instability of the support surface, resulting in muscle contraction of the GM to overcome instability ${ }^{(14)}$. In addition, the incline at $10^{\circ}$ limited the ankle dorsiflexion to $50 \%$, resulting in instability of the ankle, and cocontraction of the muscles. To overcome instability, the gluteus maximus muscle activity increased ${ }^{(\mathbf{1 5})}$.

Vianna et al. ${ }^{(16)}$ reported that the half-squat exercise was significantly higher in energy expenditure than the other exercises such as bench press, triceps extension, and lat pull down.

Kongsgaard et al. ${ }^{(17)}$ revealed with this study an increase in muscle activity of the knee extensor muscle during a squat when the ankle joint angle was increased to $25^{\circ}$ compared to doing a squat with the ankle joint angle at neutral.

Also, the results of this study corporate with Richards et al. ${ }^{(18)}$ who indicated that a gradual increase of the ankle joint is helpful for rehabilitation of the knee joint in training of athletes. Lee et al. ${ }^{(19)}$ demonstrated that when the upper body is leaned forward in squat position, it was found that the muscle activity of the erector spinae, gluteus maximus, and biceps femoris increased.

Pollard and Sigward ${ }^{(20)}$ also, support the result of this paper who said that limiting ankle dorsiflexion ROM during the squatting task resulted in decreased activity of the quadriceps musculature. Yavuz et al. ${ }^{\text {(21) }}$ observed that higher vastus medialis EMG activities during front squat with lower loads compared to back squat. Caterisano et al. ${ }^{(22)}$ showed that squat depth is very important in activation of the GM as its activity increased with the increase of squat depth. The capacity of achieving a higher depth during the back squat is associated with maximal ankle dorsiflexion range of motion when the knee is flexed and in a closed-chain condition (i.e., lunge test), but not when the knee is fully extended and in an open-chain condition ${ }^{(23)}$.

In this study, it was confirmed that the squat movement at $10^{\circ}$ of incline significantly increased the muscle activity of the GM than the squat at neutral or at $5^{\circ}$ of incline. It is considered that the increase of the base angle causes the limitation of the movement of the ankle joint, which causes the center of gravity to move backward and this also causes the increase of the muscle activity of VMO.

This study suggests that this method of intervention can be an effective method of improving the health and strength of the lower limbs of normal and athletes.

\section{CONCLUSION}

Modification of ankle dorsiflexion during squat position should be integrated in the rehabilitation programs of the different injuries.

\section{REFERENCES}

1- Chae W, Jung H, Jang J (2007): Effect of different heel plates on muscle activities during the squat. Korean $\mathbf{J}$ Sport Biomech, 17: 113-121.

2- Escamilla R (2001): Knee biomechanics of the dynamic squat exercise. Med Sci Sports Exerc., 33: 127-141.

3- Selseth A, Dayton M, Cordova M (2000): Quadriceps concentric EMG activity is greater than eccentric EMG activity during the lateral step-up exercise. J Sport Rehabil., 9: 124-134.

4- Bloomquist K, Langberg H., Karlsen $S$ et al. (2013). Effect of range of motion in heavy load squatting on muscle and tendon adaptations. European Journal of Applied Physiology, 113: 2133-2142.

5- Rippetoe M (2007): Starting Strength: Basic Barbell Training, p.8. The Aasgaard Company.https://www.amazon.com/Starting-StrengthBasic-Barbell-Training/dp/0982522738

6- Gary K (2004): Electromyographic Kinesiology. In Robertson, DGE et al. Research Methods in Biomechanics. Champaign, IL: Human Kinetics Publ., Pp. 440.

https://www.ncbi.nlm.nih.gov/pmc/articles/PMC391857 $5 /$

7- Dionisio V, Almeida G, Duarte $M$ et al. (2008): Kinematic, kinetic and EMG patterns during downward squatting. Journal of Electromyography and Kinesiology, 18: $134-143$.

8- Shahid S (2004).Higher order statistics techniques applied to EMG signal analysis and characterization. Ph.D. thesis, University of Limerick; Ireland.

9- Kendall F, McCreary E, Provance $P$ et al. (2005): Muscles: testing and function with posture and pain. Baltimore: Lippincott Williams \& Wilkins. https://www.scirp.org/(S(351jmbntvnsjt1aadkposzje))/ref erence/ReferencesPapers.aspx?ReferenceID=2060790 
10- Donatelli R (1987): Abnormal biomechanics of the foot and ankle. J Orthop Sports Phys Ther., 9: 11-6.

11- McGinty G, Irrgang J, Pezzullo D (2000): Biomechanical considerations for rehabilitation of knee. Clin Biomech (Bristol, Avon), 15: 160-6.

12- Isear J, Erickson J, Worrell T (1997): EMG analysis of lower extremity muscle recruitment patterns during an unloaded squat. Med Sci Sports Exerc., 29: 532-9.

13- Hamill J, Knutzen K (2003): Biomechanical basis of human movement. Philadelphia: Lippincott Williams \& Wilkins. https://www.amazon.com/Biomechanical-BasisMovement-Joseph-Hamill/dp/1451177305

14- Saeterbakken A, Fimland M (2013): Muscle force output and electromyographic activity in squats with various unstable surfaces. J Strength Cond Res., 27: 1306.

15- Shumway-Cook A, Woollacott M (2001): Normal postural control Motor control: translation research into clinical practice. Philadelphia: Lippincott Williams \& Wilkins, Pp. 158-86

16- Vianna J, Lima J, Saavedra F et al. (2011): Aerobic and anaerobic energy during resistance exercise at $80 \% 1 \mathrm{RM}$. J Hum Kinet., 29: 69-74.

17- Kongsgaard M, Aagaard P, Roikjaer S et al. (2006): Decline eccentric squats increases patellar tendon loading compared to standard eccentric squats. Clin Biomech (Bristol, Avon), 21:748-54.

18- Richards J, Selfe J, Sinclair J et al. (2016): The effect of different decline angles on the biomechanics of double limb squats and the implications to clinical and training practice. J Hum Kinet., 52: 125-38.

19- Lee T, Song M, Kwon Y (2016): Activation of back and lower limb muscles during squat exercises with different trunk flexion. J Phys Ther Sci., 28:3407-10.

20- Pollard C, Sigward S (2010): Powers CM. Limited hip and knee flexion during landing is associated with increased frontal plane knee motion and moments. Clin Biomech (Bristol, Avon), 25:142-146.

21- Yavuz H, Erdağ D, Amca A et al. (2015): Kinematic and EMG activities during front and back squat variations in maximum loads. J Sports Sci., 33: 1058-1066.

22- Caterisano A, Moss R, Pellinger et al. (2002): The effect of back squat depth on the EMG activity of 4 superficial hip and thigh muscles. Journal of Strength \& Conditioning Research, 16(3): 428-432.

23- Dill K, Begalle R, Frank B et al. (2014): Altered knee and ankle kinematics during squatting in those with limited weight-bearing-Lunge ankle-dorsiflexion range of motion. Journal of Athletic Training, 49: 723-732. 